\title{
Impact of roads on biodiversity: a case study from Karekhola rural road in Surkhet district of Nepal
}

\begin{abstract}
J. K. KC ${ }^{1}$ and A. P. Gautam ${ }^{2}$
Loss and degradation of biodiversity is continuing despite the past conservation efforts in Nepal. Out of many potential causes, this study strives to investigate the effects of a road project on biodiversity in the Middle Hills of Nepal. Information about floristic composition was collected from the adjoining community forests using group of 30 circular sample plots, each located at $50 \mathrm{~m}$ and $20 \mathrm{~m}$ far from the edge of the road. Results provide evidence that rural road projects are contributing to reduction of biodiversity which may be due to the removal of low-yielding timber species near the road-edge. The study also suggests that proximity to road-edge reduces understorey vegetation which will lead less capable forest to sustain its original biodiversity. However, silvicultural operations have potential to minimize the indirect loss of biodiversity caused by road projects.
\end{abstract}

Key words: Community forests, Middle Hills, rural road, woody plant species' diversity

$\mathrm{D}$ iversity of species plays an important role in ecosystem functions and services. Nepal possesses a disproportionately high diversity of flora and fauna at genetic, species and ecosystem levels due to its unique geographic position and altitudinal variations. The Government of Nepal (GoN) is committed to the protection and management of biological resources and their diversity on a sustainable basis (MFSC, 2014). As a signatory country of the Convention on Biological Diversity (CBD), the GoN has revised the country's National Biodiversity Strategy and Action Plan (NBSAP) in 2014. In addition, the GoN has put a lot of efforts in the past regarding implementation of International agreements as well as formulation of strategies to include the local communities in biodiversity conservation. However, the efforts made so far mainly relate to reducing poaching, trade and illegal activities within the protected areas. Other threats like unplanned road projects, the key causes of habitat loss and fragmentation, are usually underestimated. The problem is not restricted to motorways. However, narrow country roads occupy less area per kilometer, and are more frequent than motorways, so their combine effect upon the landscape can be considerably larger (Seiler, 2001).

Road provides a basis for long-term development in the rural areas, but the environmental consequences cannot be neglected only foreseeing economy. Unplanned and wrongly designed economic development can cause destabilization of the natural environment, which is evidenced by many past efforts in Nepal and elsewhere. Earlier studies (WWF, 2013; MFSC, 2014) have found that unplanned rural roads constructed by the local governments are one of the major threats to environment and biodiversity. The Department of Roads estimates that around 25,000 kilometers rural road tracks had been opened in Nepal by 2010, most of which have been constructed without any environmental safeguard (DOR, 2010).

Forest roads are termed as "ecosystems" as they occupy ecological space (Hall et al., 1992) and provide habitat for associated plants and animals (Lugo and Gucinski, 2000). Road infrastructure causes direct and indirect loss in forest ecosystem. Direct loss refers to the reduction of forest area and indirect loss of roads refers to fragmentation and degradation of the ecosystem (Geneletti, 2003). One of the major effects of roads relates to its edge effects, which can be defined as the alternation to habitat quality due to proximity to edge. It can cause indirect loss of habitat by changing species composition, temperature, moisture, light availability and wind speed and, therefore, alteration in original biodiversity (Gysel, 1951). The effect of edge on plant

${ }^{1}$ Building Climate Resilience of Watersheds in Mountain Eco-regions Project, Dadeldhura, Nepal.

E-mail: jibeshkc2012@gmail.com

${ }^{2}$ Kathmandu Forestry College, Kathmandu, Nepal 
diversity can occur up to $30 \mathrm{~m}$ far from the road or even beyond (Seiler, 2001).

The study was, moreover, a descriptive research limited to investigating the impacts of road projects on diversity of woody plant species. In order to assess the impacts of roads on diversity of woody plant species, the effects mainly upon the species diversity and the structural diversity were investigated. These indirect effects of road projects were assessed by comparing and analyzing woody plant species distribution in between two effect-zones $(20 \mathrm{~m}$ and $50 \mathrm{~m}$ far from road-edge).

\section{Materials and methods}

\section{Study area}

The study area is located between $28^{\circ} 36^{\prime} 14^{\prime \prime} \mathrm{N}$ and $28^{\circ} 36^{\prime} 20^{\prime \prime} \mathrm{N}$ latitude and between $81^{\circ} 38^{\prime} 19^{\prime \prime}$ $\mathrm{E}$ and $81^{\circ} 38^{\prime} 58^{\prime \prime} \mathrm{E}$ longitude in the adjoining forests of the Karekhola Rural Road. The road connects Jarbuta Village Development Committee (VDC) and Birendranagar Municipality of Surkhet District situated in the Middle Hills (Fig. 1). The earthen road is $5 \mathrm{~m}$ wide and $1.46 \mathrm{~km}$ long. The study was conducted in 2012.
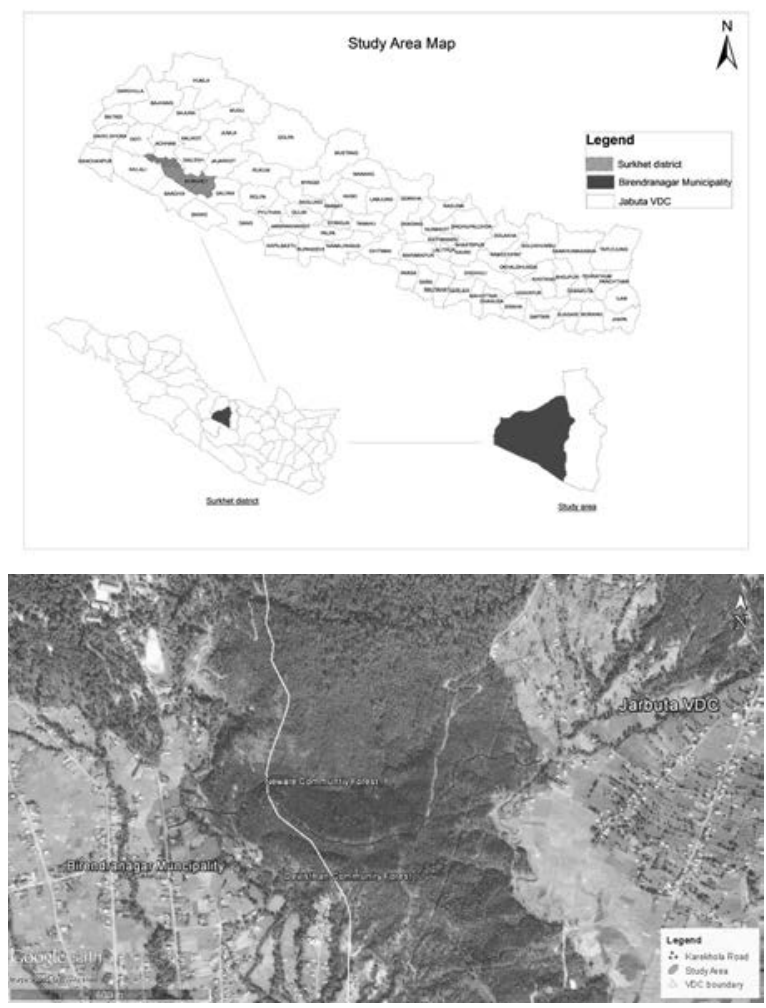

Fig. 1: Map showing the location of the study area in Western Nepal
The road is the main pillar in the development of Jarbuta VDC area. All kinds of traffic are being used to transport essential goods to meet livelihood requirements of the people of Jarbuta VDC. The road passes through Neware Community Forest (CF) in the northern part and Devis than CF in the southern part. The adjoining CFs are managed by the local Community Forest User Groups (CFUGs) according to the respective operational plans. The FUGs have deployed the locally-hired forest guards for protection of the forests.

\section{Methodology}

Systematic sampling was used for the collection of primary data on diversity of woody species in the CFs. First of all, reconnaissance survey was carried out and the Karekhola Road was surveyed with the help of GPS (Global Positioning System) Device. Preliminary data analysis was done using GIS (Geographical information System) Software. The forest area lost due to road construction was determined by multiplying the length of the road with its width. Similarly, the spacing between the two successive plots $(45 \mathrm{~m})$ was determined on the basis of different factors, such as length of the $\operatorname{road}(1.46 \mathrm{~km})$, maximum coverage of the road in the study area and the possibility of intersection of the area of the sample plots on the road bends.

Then from the starting point (on the road), $45 \mathrm{~m}$ distance was marked on the road-length with the help of a Measuring Tape. Making perpendicular to the road length, concentric circular sample plots (CCSPs) with $1 \mathrm{~m}, 3 \mathrm{~m}$ and $10 \mathrm{~m}$ radii were laid out at $20 \mathrm{~m}$ and $50 \mathrm{~m}$ distances from both the edges of the road (Fig. 1 and 2) with the help of the Measuring Tape. The sampling protocol developed and used by the International Forestry Resources and Institutions Research Network (IFRIRN) was used for assessing the forest conditions (IFRI, 2013). This research protocol has been widely used by the researchers in the past (Gautam, 2002; Gautam, 2006). In the innermost circle of the plot ( $1 \mathrm{~m}$ radius), all the woody seedlings were identified and counted. In the next circle ( $3 \mathrm{~m}$ radius), all the shrubs, saplings, and climbers were identified and counted, and also the diameters and the heights of the woody stems having diameter at breast height (DBH) in $2.5-10 \mathrm{~cm}$ class were recorded. In the largest circle (10 $\mathrm{m}$ radius), all the stems with $10 \mathrm{~cm}$ or greater DBH were counted, and their diameters and heights measured. The same 
process was repeated from the opposite edge of the road. Again, at the distance of $45 \mathrm{~m}$ from the previous location, the same process was repeated. In this way, altogether 30 circular sample plots were laid at $20 \mathrm{~m}$ and $50 \mathrm{~m}$ distances from the road-edge throughout the study area.

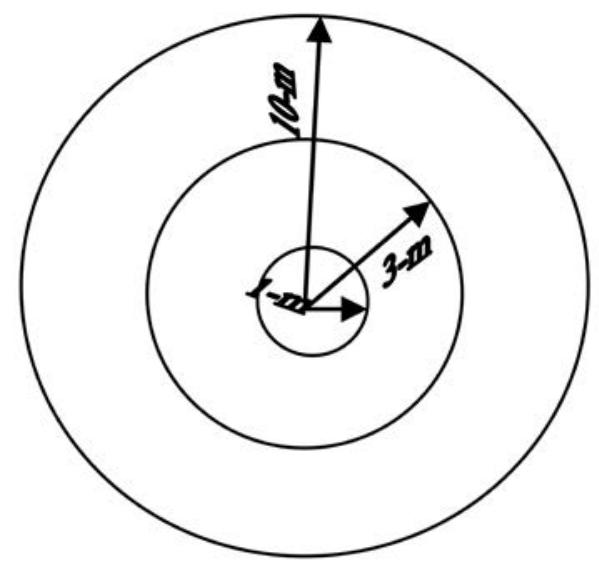

Fig. 2: A concentric circular sample plot

The woody plant species' diversity was assessed and compared using the Simpson's Diversity Index (D) and the Sorenson's Similarity Index (SSI).

Simpson's Diversity Index (D): It gives the probabilities that the two randomly chosen individuals drawn from a population belong to the same species. Higher the probabilities that both the individuals belong to the same species, lower the diversity. For finite communities (where all members have been counted),

Simpson's Diversity Index (D) $=\sum \mathrm{pi}^{2}$

(Baral and Katzensteiner, 2009),

Where, pi is the proportional abundance of the ith species i.e. the proportion of individuals of a given species relative to the total no. of individual in an effect-zone (i.e. forest stand).

Sorenson's Similarity Index (SSI): It is a very simple measurement of beta diversity. The SSI value ranges from 0 where there is no species overlap between the effect-zones to 1 when exactly the same species are found in both the effect-zones.

Sorenson's Similarity Index $(\mathrm{SSI})=2 \mathrm{c} /\left(\mathrm{S}_{1}+\mathrm{S}_{2}\right)$ (Magurran, 1988),
Where,

$\mathrm{S}_{1}=$ Total no. of species found in the CCSP located at $20 \mathrm{~m}$ distance from the road edge,

$\mathrm{S}_{2}=$ Total no. of species found in the CCSP located at $50 \mathrm{~m}$ distance from the road edge, and $\mathrm{C}=$ No. of species common to both the effectzones.

\section{Structural diversity}

In order to compare the structural diversity of the two effect-zones, the DBH and height distribution classes were prepared. The diameters (at breast height) were categorized into the classes of $0-5$ $\mathrm{cm}, 5-10 \mathrm{~cm}, 10-15 \mathrm{~cm}$, and above $15 \mathrm{~cm}$. Then, the DBH class distributions between the two zones were compared, and analyzed. Similarly, the heights were categorized into the classes of 1-5 $\mathrm{m}, 5-10 \mathrm{~m}$, and above $10 \mathrm{~m}$, and the heights between the two zones were also compared and analyzed.

\section{Results and discussion}

Plant species found in the two types of effectzones

Altogether, 23 plant species including 18 tree species, 3 shrub species and 2 woody climber species were found in the study area. A total of 19 plant species were found in the effect-zone at 20 $\mathrm{m}$ distance while a total of 16 plant species were found in the effect-zone at $50 \mathrm{~m}$ distance. Seven tree species, three shrub species and two woody climbers were common in both the effect-zones (Table 1). The difference in species richness between the two zones could be due to the edge effects, which often results higher species richness and greater numbers of exotic species at the edges (Ranney et al., 1981), and potential ecosystem processes and productivity function alters (Laurance et al., 1997).

The calculated Sorenson's Similarity Index (SSI) value of the two effect-zones was found to be 0.69 (near to value 1) which indicated that the species found in both the effect-zones were more or less similar. Shorea robusta was found to be the dominant tree species in both the effect-zones. Other common tree species noticed were Dalbergia sissoo, Terminalia alata and Buchanania latifolia. Similarly, Argemore maxicana was found to be the principal shrub species in both the effect-zones. 
Table 1: List of the plant species found in the two effect-zones

\begin{tabular}{|c|c|c|c|c|}
\hline S.N. & Local Name & Botanical Name & $20 \mathrm{~m}$ distance & $50 \mathrm{~m}$ distance \\
\hline 1. & $\operatorname{Sal}(\mathrm{T})$ & Shorea robusta & $\sqrt{ }$ & $\sqrt{ }$ \\
\hline 2. & Sissoo $(\mathrm{T})$ & Dalbergia sissoo & $\sqrt{ }$ & $\sqrt{ }$ \\
\hline 3. & Jamun $(\mathrm{T})$ & Syzigium cumini & $\sqrt{ }$ & $\sqrt{ }$ \\
\hline 4. & Khirro (T) & Wrightia arborea & $\sqrt{ }$ & \\
\hline 5. & Tate $(\mathrm{T})$ & Sapindus mukorossi & $\sqrt{ }$ & \\
\hline 6. & Ranisalla $(\mathrm{T})$ & Pinus roxbughii & & $\sqrt{ }$ \\
\hline 7. & Khannyu (T) & Ficus semicordata & & $\sqrt{ }$ \\
\hline 8. & Pyar (T) & Buchanania latifolia & $\sqrt{ }$ & $\sqrt{ }$ \\
\hline 9. & Tilka $(\mathrm{T})$ & Wendlendia appendiculata & $\sqrt{ }$ & $\sqrt{ }$ \\
\hline 10. & Bhorla (W) & Bauhinia vahlli & $\sqrt{ }$ & $\sqrt{ }$ \\
\hline 11. & Bhalayo $(\mathrm{T})$ & Rhus wallichii & $\sqrt{ }$ & \\
\hline 12. & Bot dhanyero $(\mathrm{T})$ & Largerstromia parviflora & $\sqrt{ }$ & \\
\hline 13. & Gaitihare $(\mathrm{T})$ & Inula cappa & & $\sqrt{ }$ \\
\hline 14. & Saj $(\mathrm{T})$ & Terminalia alata & $\sqrt{ }$ & $\sqrt{ }$ \\
\hline 15. & Imili (T) & Tamarindus indica & $\sqrt{ }$ & $\sqrt{ }$ \\
\hline 16. & Kyamuno $(\mathrm{T})$ & Syzigium cerasoides & $\sqrt{ }$ & \\
\hline 17. & Mauwa $(\mathrm{T})$ & Madhuca indica & $\sqrt{ }$ & \\
\hline 18. & Amba $(T)$ & Psidium guajava & $\sqrt{ }$ & \\
\hline 19. & Latimauwa (S) & Engelhardia spicata & $\sqrt{ }$ & $\sqrt{ }$ \\
\hline 20. & Kutmero (T) & Litsea monopetala & & $\sqrt{ }$ \\
\hline 21. & Mainfalkada (S) & Catuna regamspinosa & $\sqrt{ }$ & $\sqrt{ }$ \\
\hline 22. & Badulpate (W) & Cissampelos pareira & $\sqrt{ }$ & $\sqrt{ }$ \\
\hline 23. & Thakkal (S) & Argemore maxicana & $\sqrt{ }$ & $\sqrt{ }$ \\
\hline
\end{tabular}

Note: $\mathrm{T}=$ Tree, $\mathrm{S}=$ Shrub and $\mathrm{W}=$ Woody climber

\section{Species diversity of trees}

Altogether, 11 plant species were found to be at tree stage in the effect-zone at $20 \mathrm{~m}$ distance while a total of 10 plant species were found to be at that stage in the effect-zone at $50 \mathrm{~m}$ distance (Table 1). For the higher plant species diversity, the number of plant species present in an effectzone is not so important, but the even distribution of each individual plant species within the zone is important. In the effect-zone at $50 \mathrm{~m}$ distance, the plant species were found to be evenly distributed as compared to the one in the effect-zone at 20 $m$ distance. The Simpson's Diversity Index (D) was found to be 0.6057 in the effect-zone at 50 $\mathrm{m}$ distance while it was 0.7113 at $20 \mathrm{~m}$ distance (Table 2). Thus, the value of $\mathrm{D}$ was found to be slightly less within the effect-zone at $50 \mathrm{~m}$ distance as compared to the one within the effectzone at $20 \mathrm{~m}$ distance, which showed that the effect-zone at $50 \mathrm{~m}$ distance was rich in plant diversity as compared to the effect-zone at $20 \mathrm{~m}$ distance due to the road-edge effects.

Table 2: Simpson's Diversity Index values in the two effect-zones

\begin{tabular}{lclr}
\hline S.N. & $\begin{array}{c}\text { Forest stand } \\
\text { (effect-zone) }\end{array}$ & $\begin{array}{c}\text { Stage of the } \\
\text { plants }\end{array}$ & $\begin{array}{c}\text { Simpson's } \\
\text { Index (D) }\end{array}$ \\
\hline 1. & At $20 \mathrm{~m}$ distance & Tree & 0.7113 \\
& & Sapling & 0.7187 \\
& & Seedling & 0.4449 \\
2. & \multirow{2}{*}{ At $50 \mathrm{~m}$ distance } & Tree & 0.6057 \\
& & Sapling & 0.6850 \\
& & Seedling & 0.3881 \\
\hline
\end{tabular}

\section{Species diversity of saplings}

Altogether, 7 plant species at sapling stage were found in the effect-zone at $20 \mathrm{~m}$ distance while a total of 9 plant species at that stage were found in 
the effect-zone at $50 \mathrm{~m}$ distance. A total number of 167 and 225 saplings of S. robusta were recorded in the effect-zones at $20 \mathrm{~m}$ distance and $50 \mathrm{~m}$ distance, respectively. S. robusta was found to be unevenly distributed in the effect-zone at $20 \mathrm{~m}$ distance than in the effect-zone at $50 \mathrm{~m}$ distance; other plant species were found to be in very few numbers. On the contrary, other species were found to be evenly distributed in the effectzone at $50 \mathrm{~m}$ distance in spite of the dominancy of S. robusta. The Simpson's Diversity Index was found to be 0.7187 in the effect-zone at 20 $\mathrm{m}$ distance and 0.6850 in the effect-zone at 50 $\mathrm{m}$ distance, indicating a little bit higher plant diversity in the effect-zone at $50 \mathrm{~m}$ distance than in the effect-zone at $20 \mathrm{~m}$ distance. The result also showed that the forest stand (effect-zone) at $50 \mathrm{~m}$ distance was richer in species diversity at sapling stage as compared to the one at $20 \mathrm{~m}$ distance.

\section{Species diversity of seedlings}

Altogether, 10 plant species were found at seedling stage in the effect-zone at $50 \mathrm{~m}$ distance while 11 plant species were noticed at that stage in the effect-zone at $20 \mathrm{~m}$ distance. A total of 242 seedlings of $S$. robusta were found to be distributed in the effect-zone at $20 \mathrm{~m}$ distance while a total of 205 seedlings of this species were found in the effect-zone at $50 \mathrm{~m}$ distance. The Simpson's Diversity Indices were found to be 0.4449 and 0.3881 in the effect-zones at $20 \mathrm{~m}$ and $50 \mathrm{~m}$ distances, respectively (Table 2 ). The result showed that the effect-zone at $50 \mathrm{~m}$ distance possessed more plant diversity at seedling stage as at tree and sapling stages than the effect-zone at $20 \mathrm{~m}$ distance due to the proximity to the roadedge.

In the community-managed forests, removal of bigger and older trees is carried out during silvicultural operations so as to provide space for preferred species of younger trees (Baral and Katzensteiner, 2009). Due to the removal of older trees, appropriate environment is created to regenerate new crop and also establishment of the younger ones which leads the forest towards more diverse in undergrowth. Suding (2001) carried out one of the several studies which also documented proportionate relationship between species richness and light availability on the forest floor.

\section{Structural diversity}

Moreover, dominant trees with $10-15 \mathrm{~cm}$ DBH class and 5-10 $\mathrm{m}$ height class were found to be distributed in the study area. Trees with higher DBH classes (10-15 cm and above $15 \mathrm{~cm})$ and higher height classes $(5-10 \mathrm{~m}$ and above $10 \mathrm{~m})$ were found to be distributed more in the effectzone at $20 \mathrm{~m}$ distance than in the effect-zone at $50 \mathrm{~m}$ distance (Fig. 3 and 4). On the contrary, plants with lower DBH classes $(0-5 \mathrm{~cm}$ and 5-10 $\mathrm{cm})$ and lower height class $(0-5 \mathrm{~m})$ were found to be distributed more in the effect-zone at $50 \mathrm{~m}$ distance than in the effect-zone at $20 \mathrm{~m}$ distance. The study indicated that the under-storey vegetation in the effect-zone at $20 \mathrm{~m}$ distance was comparatively lesser than that in the effectzone at $50 \mathrm{~m}$ distance. This reveals that the roads affect not only upon plant species' diversity but also have potential impact on structural diversity. This also reveals that proximity to road edge reduces under-storey vegetation and results less sustainable forest.

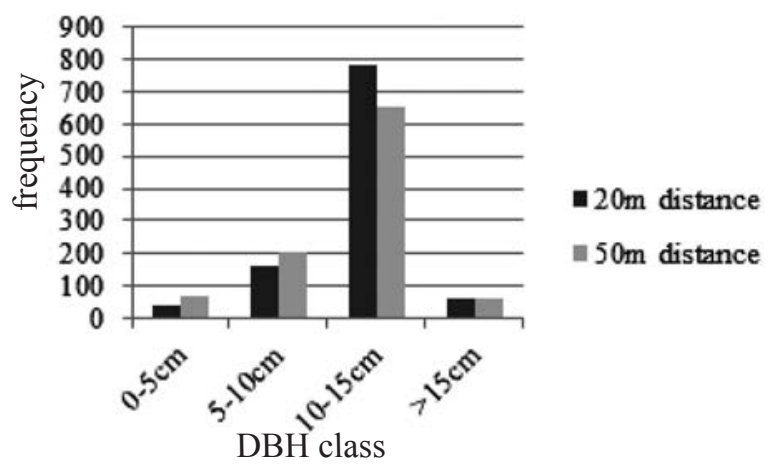

Fig. 3: Plant distribution in terms of DBH classes in the two effect-zones

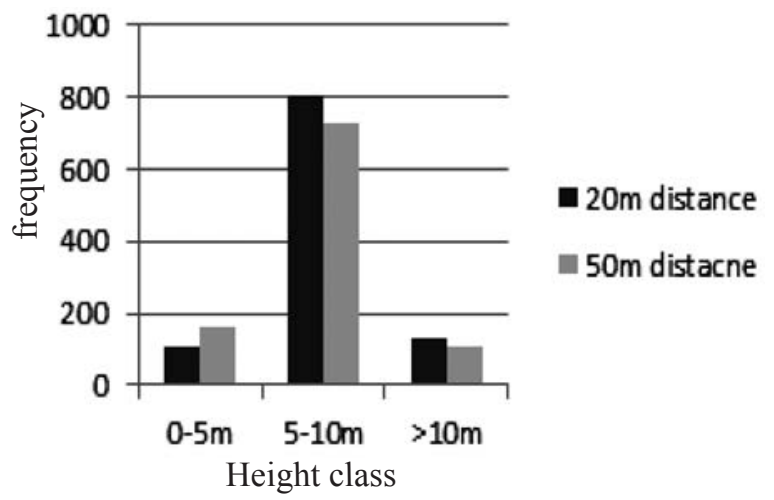

Fig. 4: Plant distribution in terms of height classes in the two effect-zones

Several studies show that silvicultural practices can have a positive or neutral effect on understorey plant species richness (Jenkins and Parkers, 
1999). So, proper silviculture practices can, to some extent, reduce the effects of road-edge on the forests. Nevertheless, the number of plant species is not only one component of biological diversity that should be considered; under-storey species composition, spatial scale, number of endemic species and taxonomic singularity of the elements must also be taken into consideration (Ojeda et al., 1995; Zavala and Oria, 1995).

\section{Distribution of major plant species}

S. robusta, T. alata, Syzigium cumini, D. sissoo, A. maxicana and Engelhardia spicata were categorized as major species and the rest were categorized as others for the purpose of the study. At tree stage, S. robusta was found to be unevenly distributed in the effect-zone at $20 \mathrm{~m}$ distance than in the effect-zone at $50 \mathrm{~m}$ distance (Fig. 5a), and other major species were either almost equally distributed (e.g. T. alata) in both effect-zones or more distributed (S. cumini and D. sissoo) in the effect-zone at $50 \mathrm{~m}$ distance (Table $5 \mathrm{~b}$ ).

At sapling stage, all the major plant species were found to be distributed higher in the effect-zone at $50 \mathrm{~m}$ distance than in the effect-zone at 20 $\mathrm{m}$ distance. The distribution of other species at sapling stage was higher in the effect-zone at 20 $\mathrm{m}$ distance. At sapling stage, only Catunaregam spinosa was found to be distributed in the effectzone at $50 \mathrm{~m}$ distance, but fodders like Ficus semicordata and Listea monopetala were not detected at sapling stage in the effect-zone at $20 \mathrm{~m}$ distance. At seedling stage, S. robusta, $T$. alata, S. cumini and C. spinosa were found to be in higher distribution in the effect zone at $20 \mathrm{~m}$ distance than in the effect-zone at $50 \mathrm{~m}$ distance.

On the other hand, all the three shrub species viz. E. spicata, C. spinosa and A. maxicana were found to be equally distributed at their seedling stage in both the effect-zones. On the other hand, the two species of woody climber viz. Cissampelo spareira and Bauhinia vahlli were also found to be less distributed in the effect-zone at $20 \mathrm{~m}$ distance.

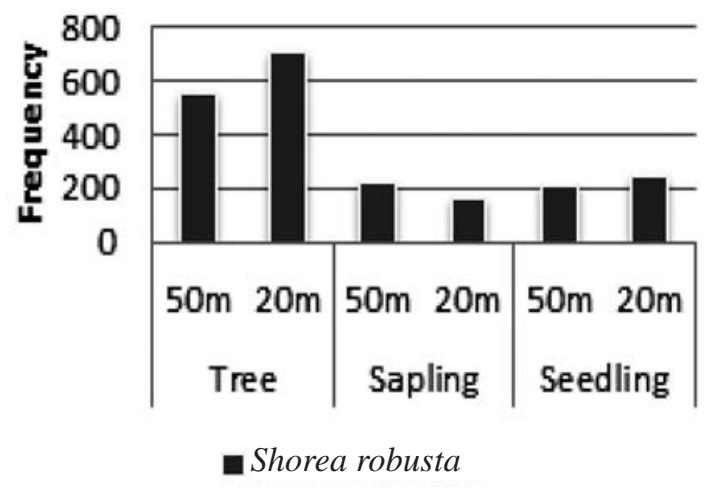

Fig. 5a: Distribution of $S$. robusta at different stages in the two zones

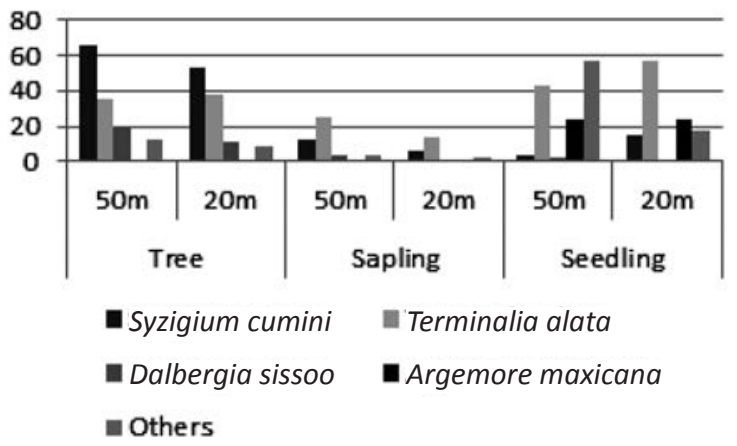

Fig. 5b: Distribution of major plant species except $S$. robusta at different stages in two zones

Communities are highly promoting and protecting timber yielding trees like $S$. robusta even in mixed S. robusta forest (Ojha and Bhattarai, 2001; Acharya, 2003) at the expenses of low quality timber-yielding species and shrubs (Kandel, 2007 cited by Shrestha et al., 2010; Acharya et al., 2007; Shrestha, 2005), which may be one of the causes behind the less woody plant species' diversity in the effect-zone at $20 \mathrm{~m}$ distance. Proximity to road-edge makes easy to remove other valuable species from the forest.

\section{Conclusion}

The study indicates that roads bring about adverse impacts upon the woody plant species diversity in the adjoining forests. Proximity to road-edge reduces species diversity due to removal of lowyielding timber species. The findings of the study also reveal that the effects of road-edge cause reduction in under-storey vegetation. However, the removal of over mature, dead, dying, diseased and deformed trees can have positive effects upon the species diversity in the forest. Therefore, silvicultural operations should be carried out 
in the forests nearby roads so as to mitigate the adverse impacts caused by the roads.

\section{References}

Acharya, K. P. 2003. Conserving biodiversity and improving livelihoods: the case of community forestry in Nepal. Paper presented in International Conference on Rural Livelihood, Forests and Biodiversity, Bonn, Germany, 9-13.

Acharya, K. P., Gautam, K. R., Acharya, B. K. and Gautam, G. 2007. Participatory assessment of biodiversity conservation in community forestry in Nepal. Banko Janakari 16: 46-56.

Baral, S. K. and Katzensteiner, K. 2009. Diversity of vascular plant communities along a disturbance gradient in a central mid-hill community forest of Nepal. Banko Janakari 19 (1): 3-10.

DOR. 2010. Statistics of Strategic Road Networks (2009/10). Department of Roads (DOR), Kathmandu, Nepal.

Gautam, A. P. 2002. Forest Land Use Dynamics and Community-based Institutions in a Mountain Watershed in Nepal: Implications for Forest Governance and Management. Ph.D. Dissertation, Asian Institute of Technology, Thailand, xi-174.

Gautam, A. P. 2006. Combining geomatics and conventional methods for monitoring forest conditions under different governance arrangements. Journal of Mountain Science 3 (4): 325-333.

Geneletti, D. 2003. Biodiversity Impact Assessment of roads: an approach based on ecosystem rarity. Environment Impact Assessment Review 23 (2003): 343-365.

Gysel, W. L. 1951. Borders and openings of beechmaple woodlands in southern Michigan. Journal of Forestry 49: 13-19.

Hall, C. A. S., Stanford J. A. and Hauer, R. 1992. The distribution and abundance of organisms as consequence of energy balances along multiple environmental gradients. Oikos 65: 377-390.
IFRI. 2013. International Forestry Resources and Institutions (IFRI) Network: Research Methods. http:/ www.ifriresearch.net (accessed on: 12 December, 2015).

Jenkins, M. A. and Parker, G. R. 1999. Composition and diversity of groundlayer vegetation in silvicultural openings of Southern Indiana Forests. The American Midland Naturalist 142: 1-16.

Laurance, W. F., Laurance, S. G., Ferreira, L. V., Merona, J. M. R., Gascon, J. M. R. and Lovejoy, T. E. 1997. Biomass collapse in Amazonian forest fragments. Science 278: 1117-1118.

Lugo, A. E. and Gucinski, H. 2000. Function, effects and management of forest roads. Forest Ecology Management 133: 249-262.

Magurran, A. E. 1988. Ecological Diversity and its Measurement. Princeton University Press, Princeton, USA.

MFSC. 2014. National Biodiversity Strategy and Action Plan. Ministry of Forests and Soil Conservation (MFSC), Kathmandu, Nepal, 20-28.

Ojeda, F., Arroyo, J. and Maranon, T. 1995. Biodiversity components and conservation of Mediterranean heathlands in Southern Spain. Biological Conservation 72: 61-72.

Ojha, H. R. and Bhattarai, B. 2001. Understanding community perspectives of silvicultural practices in the middle hills of Nepal. Forests, Trees and People Newsletter 40: 55-61.

Ranney, J. W., Bruner, M. C. and Leenson, J. B. 1981. The importance of edges in the structure and dynamics of forest islands. In Forest island dynamics in a man-dominated landscape (eds) Burgess, P. L. and Sharp, D. M. Springer-Verlag, New York, USA, 67-95.

Seiler, A. 2001. Ecological Effects of Roads: A Review. Introductory Research Essay No. 9. Department of Conservation Biology, Swedish University of Agricultural Science, Upsalla, Sweden.

Shrestha, B. B. 2005. Fuelwood harvest, management and regeneration of two 
community forests in Central Nepal. Himalayan Journal of Science 3: 75-80.

Shrestha, U. B., Shrestha, B. B. and Shrestha S. 2010. Biodiversity conservation in community forests of Nepal: rhetoric and reality. International Journal of Biodiversity and Conservation 2 (5): 98-104.

Suding, K. N. 2001. The effects of gap creation on competitive interactions: separating changes in overall intensity from relative rankings. Oikos 94: 219-227.
WWF. 2013. Chitwan-Annapurna Landscape: Drivers of Deforestation and Forest Degradation. Hariyo Ban Programme, World Wildlife Fund Nepal, Kathmandu, Nepal.

Zavala, M. A. and Oria, J. A. 1995. Preserving biological diversity in managed forests: a meeting point for ecology and forestry. Landscape and Urban Planning 31: 363378. 